\title{
Effect of shear span-to-depth ratio on post- tensioned concrete crane beams shear capacity
}

\author{
Wit Derkowski*, and Rafat Walczak \\ Chair for RC and PC Structures, Cracow University of Technology, \\ 24 Warszawska St., 31-155 Cracow, Poland
}

\begin{abstract}
The shear span-to-depth ratio has the most significant influence on the shear capacity of beams and determines their failure mode. The subject of the current project is the shear capacity of precast posttensioned concrete crane beams disassembled after more than fifty years of being used in an industrial plant. The paper gives the theoretical basis for the shear capacity of such elements as well as standard design models. The conducted tests showed that despite the low shear reinforcement ratio, the elements do not fail in a brittle mode but show a clear indication of prospective destruction. It was also confirmed that in the case of poorly shear-reinforced PC elements, a clear arch action can be distinguished with a low shear spanto-depth ratio, whereas in the case of a higher ratio there is a classical beam action.
\end{abstract}

\section{Definition of the research problem}

Since the early development of concrete structure design, a consistent approach has been sought for the design of members subjected to shear without transverse reinforcement or with a low ratio of transverse reinforcement. Research on shear members is carried out continuously in numerous research centers around the world. The assessment of the shear capacity of elements without shear reinforcement or with a low ratio of transversal reinforcement is a very complex issue and is determined by a variety of parameters. The issue of shear capacity of RC members with a low amount of transverse reinforcement has been discussed by numerous researchers, however, the number of scientific works related to prestressed concrete members is very limited.

The subject of the current project is the shear capacity of precast prestressed concrete crane beams disassembled after more than fifty years of being used in an industrial plant [1]. During their service life, they served as a track for overhead cranes with a lifting capacity of 12.5 tons. The nature of the crane work makes it possible to apply the load anywhere along the length of the beam, which changes the static scheme of the element.

Although the transverse reinforcement in the crane beam's web was designed at the spacing of $150 \mathrm{~mm}$, in practice, stirrups were located irregularly: spacing ranged from 140 to $300 \mathrm{~mm}$. Smooth steel transverse reinforcement with a diameter of $8 \mathrm{~mm}$ had been used. The actual ratio of transverse reinforcement is smaller than assumed in the design and, according to the Eurocode and Model Code 2010 standards, the beams do not meet the required minimum level of $\rho_{w, \min }=0,21 \%$. 


\section{Shear slenderness effect}

The basic parameter in the shear analysis is shear slenderness, which is defined as the ratio of the bending moment to the quotient of the transverse force and effective depth of the section. In the case of simply supported beams loaded with concentrated forces, the shear slenderness is the ratio of the force application distance $a$ to the effective depth of the section $d[2]$.

The shear span-to-depth ratio has the most significant influence on the load-bearing capacity of the shear elements and determines their destruction mechanism. One of the first researchers who noticed and studied the influence of shear slenderness was Kani [3]. He studied RC elements with shear $a / d$ ratio from 1.0 to 8.0 and showed that with values $a / d$ $>2.5$ the magnitude of failure shear stress increases significantly. A significant increase in shear strength of the tested $\mathrm{RC}$ beams with a/d ratio lower than 2.5 was also observed by Bukhari and Ahmad [4]. Shuaib and Lue showed a similar relationship for reinforced concrete beams made of high strength concrete [5].

Zsutty [6] conducted a statistical analysis of the results of available experimental studies carried out on simply supported beams loaded with concentrated forces. Based on the analysis, he divided the elements into two groups: the first group consisted of elements with shear span-to-depth ratio $a / d \geq 2.5$ showing beam action, while the second group consisted of elements with $a / d$ ratio $<2.5$ showing arch action. He also proposed empirical formulas to calculate the shear capacity which depends on the shear $a / d$ ratio. Formula (1) concerns beams with $a / d \geq 2.5$, while formula (2) applies to beams with $a / d<2.5$.

$$
\begin{gathered}
V_{u l t}=11.4\left(f_{c} \cdot \rho \cdot \frac{d}{a}\right)^{1 / 3} \cdot b \cdot d \\
V_{u l t}=28.6\left(f_{c} \cdot \rho\right)^{1 / 3}\left(\frac{d}{a}\right)^{4 / 3} \cdot b \cdot d
\end{gathered}
$$

Due to the change in the action mechanism of bent elements often observed in tests with $a / d=2.5$ shear ratio, it is generally accepted to divide the elements into typical beams (with $a / d \geq 2.5)$ that show a beam action and short beams $(a / d<2.5)$ that show an arch action. The mechanism of failure of typical beams most often results from the rapid development of diagonal cracks, but the damage caused by the yielding of the longitudinal reinforcement may also occur. In the case of short beams, the load-bearing capacity is determined either by the yielding of the longitudinal reinforcement or by reaching the stress limit in the compressed concrete strut [7]. Typical failure mechanisms of RC members with varied a/d ratio are presented in Fig. 1.

The basic mechanisms involved in the transmission of shear forces are as follows:

- aggregate interlock - occurs after the inclined crack has been formed and is strongly dependent on aggregate grain size [8]. The aggregate friction is also dependent on the crack width and decreases as the crack width increases. In the UHSC, where the crack cuts through aggregate grains, the phenomenon of aggregate interlock occurs to a limited extent; - dowel action of the reinforcement - becomes visible when the inclined crack reaches the level of the longitudinal reinforcement and the rebars take over a part of the lateral force [9];

- strain-softening, which occurs in the inclined crack tip - a mechanism associated with the phenomenon of concrete weakening in the micro-cracking zone [10];

- work of uncracked concrete in the compression zone. 
The involvement of particular phenomena in the transfer of shear stress is variable during particular phases of the element's operation and has not been fully identified.

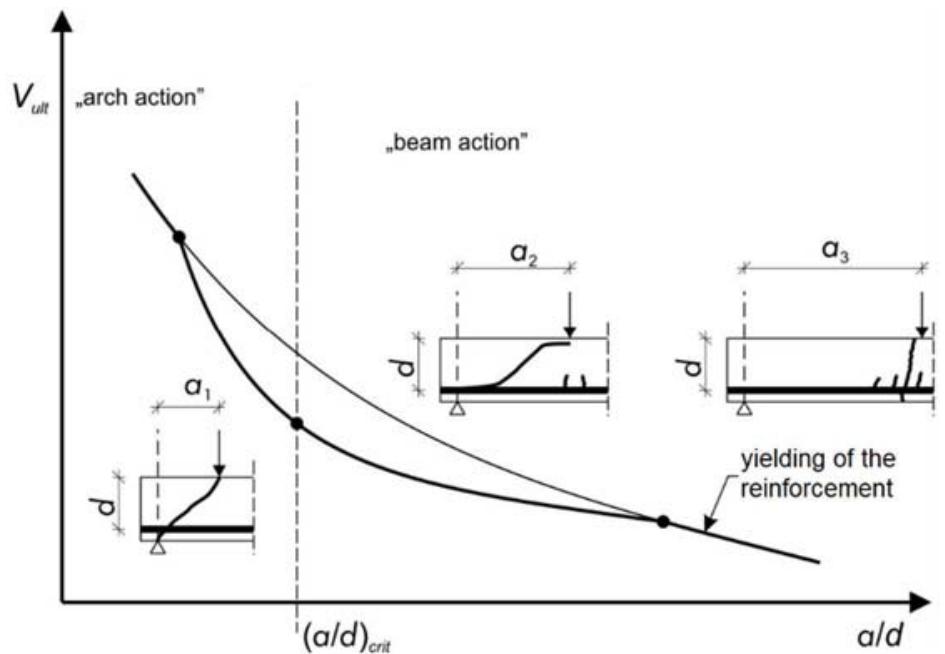

Fig. 1. Classification of the elements according to the shear action $\left(a_{1} \leq a_{2} \leq a_{3}\right)$ [7].

With the arch action of the element, a significant part of the load can be transferred through a concrete strut directly to the support, which explains the increased load capacity of elements with low shear span-to-depth ratio. The increase of stress in the strut is influenced by the appropriate anchorage of longitudinal reinforcement bars, which work as a tie. When the reinforcement has an adequate anchorage length, a loss of bearing capacity can occur by crushing the concrete strut. In the case of prestressed concrete elements, the prestressing force also counteracts shear, particularly in the case of the curvilinear tendon trajectory. It is worth noting that the prestressing reinforcement also shows dowel action after crack inclination.

\section{Shear capacity calculation models in current standards}

According to Eurocode 2 [11], the shear capacity of an element without transverse reinforcement is calculated according to formulae (3) and (4):

$$
V_{R d . c}=\left[C_{R d, c} \cdot k\left(100 \cdot \rho_{l} \cdot f_{c k}\right)^{\frac{1}{3}}+k_{1} \cdot \sigma_{c p}\right] \cdot b_{w} \cdot d
$$

but not less than:

$$
V_{R d, c}=\left[v_{\min }+k_{1} \cdot \sigma_{c p}\right] \cdot b_{w} \cdot d
$$

EN 1992-1-1 :2004 standard [11] also provides a formula (5) for calculating the shear resistance in areas non-cracked in bending for single-span, simply supported, prestressed elements:

$$
V_{R d, c}=\frac{I \cdot b_{w}}{S} \sqrt{f_{c t d}^{2}+\alpha_{1} \cdot \sigma_{c p} \cdot f_{c t d}}
$$

Equation (5) determines the shear strength of the prestressed element without the transverse reinforcement, based on the limitation of the main tensile stresses to the tensile 
strength of the concrete. It is worth adding that, according to [12], typical post-tensioned crane beams were designed for transverse force capacity by limiting the value of the main tensile stresses.

Model Code 2010 [13] gives the formulae for calculating the shear capacity of elements without and with the transverse reinforcement with a defined level of approximation. Equation (6) allows the calculation of the shear capacity of an element without the shear reinforcement. Depending on the level of approximation, the method of determining the $k_{v}$ parameter which represents the longitudinal deformation in the center of the effective shear depth changes. Approximation level I assumes a deformation of $\varepsilon_{x}=0.00125$, which corresponds to half the deformation of a $500 \mathrm{MPa}$ reinforcing steel when it is yielding. Consequently, it is not possible to analyze prestressed elements in this approximation. Approximation level II takes into account the effect of the prestressing by determining the deformation according to the cross-sectional forces. The shear capacity of elements with the transverse reinforcement according to [13] can be calculated using approximation level III from formula (7).

$$
\begin{gathered}
V_{R d, c}=k_{v} \cdot \frac{\sqrt{f_{c k}}}{\gamma_{c}} \cdot z \cdot b_{w} \\
V_{R d}=V_{R d, c}+V_{R d, s}
\end{gathered}
$$

The capacity assigned to the concrete $V_{R d, c}$ is limited by the $k_{v}$ coefficient, while the resistance of the stirrups $V_{R d, s}$ is calculated according to formula (8).

$$
V_{R d, s}=\frac{A_{s w}}{s} \cdot z \cdot f_{y w d} \cdot \cot \theta
$$

However, both Model Code and Eurocode 2 standards indicate that the design loadbearing capacity according to Equation (8) should not be used when the element does not meet the minimum transverse reinforcement requirement. Other models for determining the shear capacity of elements without or with a low transverse reinforcement ratio, which are not included in the standards, are presented in the papers [7], [14] and [15].

The shear capacity limited by crushing the compressed concrete strut according to Eurocode 2 is calculated with a formula (9) in which the $b_{w}$ value is reduced due to the presence of a cable duct:

$$
V_{R d, \max }=\frac{\alpha_{c w} \cdot b_{w} \cdot z \cdot v_{1} \cdot f_{c d}}{\cot \theta+\tan \theta}
$$

\section{Experimental tests}

The experimental tests examined precast posttensioned concrete crane beams. These are typical I-section elements, with a height of $800 \mathrm{~mm}$ and modular span of $6.0 \mathrm{~m}$ (theoretical span $-5.6 \mathrm{~m}$ ). Cross-section and the front view of the beam are shown in Fig. 2 and Fig. 3. Each beam was prestressed with five bonded cables with external steel cone anchorages. One of the beams (KBP-03) was made as an assembled two precast segments, each $2.90 \mathrm{~m}$ long. The other beams were precast entirely. 


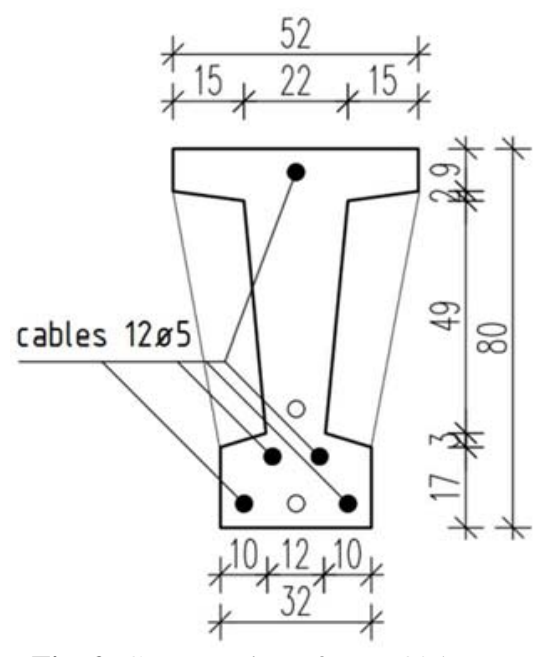

Fig. 2. Cross section of KBP 80 beam.

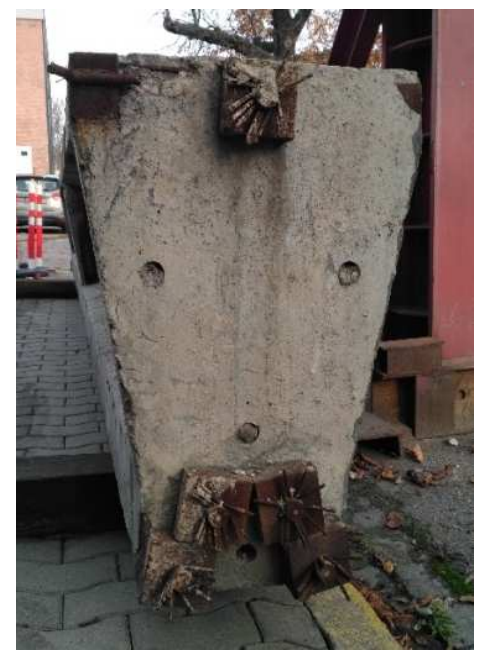

Fig. 3. Front view of the tested beam.

For experimental tests of the load-bearing capacity, a special stand was prepared for simply supported crane beams, providing one hinged-sliding support and one hinged support (no sliding). In the tests, the position of the concentrated external load was differentiated to obtain static diagrams of different shear span-to-depth ratios.

In KBP-01 specimen tests, the force was applied at the distance of $a=1.2 \mathrm{~m}$ from the support axis and for KBP-02 specimen at the distance of $a=2.0 \mathrm{~m}$. The shear a/d ratio in the considered schemes are 1.57 and 2.61, respectively. The shear $a / d$ ratio of KBP-03 specimen, tested in a three-point bending scheme with a loading force at the middle of the span, equals 3.66. The experimental setups are shown in Fig. 4.

The deflections of the element were recorded continuously by LVDT sensors in the middle of the beam span, in the cross-section loaded with concentrated force and above the supports. Concrete strain changes were recorded by a system of electrofusion strain gauges connected to the HBM measuring system which simultaneously recorded the deflection and external load. The strain gauges were arranged in pairs in a compression flange and as two rosettes of three strain gauges each, which were placed on one side of the surface of the web to determine the main strain directions. In addition, on the other side of the beam, strain changes were measured using the Digital Image Correlation method (DIC).

\section{Tests results}

The KBP-01 element was tested in a shear setup with low span-to-depth ratio and showed a distinct arch action in the support zone being destroyed by crushing a separate compressed concrete strut (see Fig. 5). The destruction of the concrete strut took place rapidly and was accompanied by the release of high energy, which resulted in the deployment of the section in the damaged support zone. The failure took place at the load $\mathrm{P}_{\exp }=1234.7 \mathrm{kN}$, i.e. the theoretical transverse force at the support, including the dead load, was $\mathrm{V}_{\exp }=983.9 \mathrm{kN}$. The maximum bending moment at the moment of failure was $\mathbf{M}_{\exp }=1177.1 \mathrm{kNm}$. The diagonal cracks which separated the concrete strut ran from the point of load application, in the direction of the support at an angle of $35-40^{\circ}$. From the DIC strain measurements, it follows that the first diagonal crack occurs at the force of $\mathrm{P}_{\mathrm{cr}}=453.8 \mathrm{kN}$, causing the cross-sectional forces: $\mathrm{V}_{\mathrm{cr}}=370.3 \mathrm{kN}$ and $\mathrm{M}_{\mathrm{cr}}=440.9 \mathrm{kNm}$. 
a)

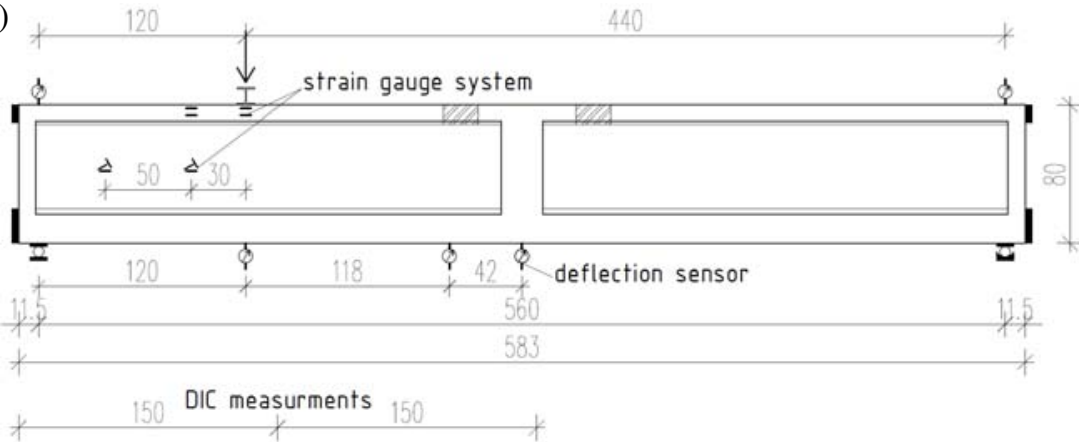

b)

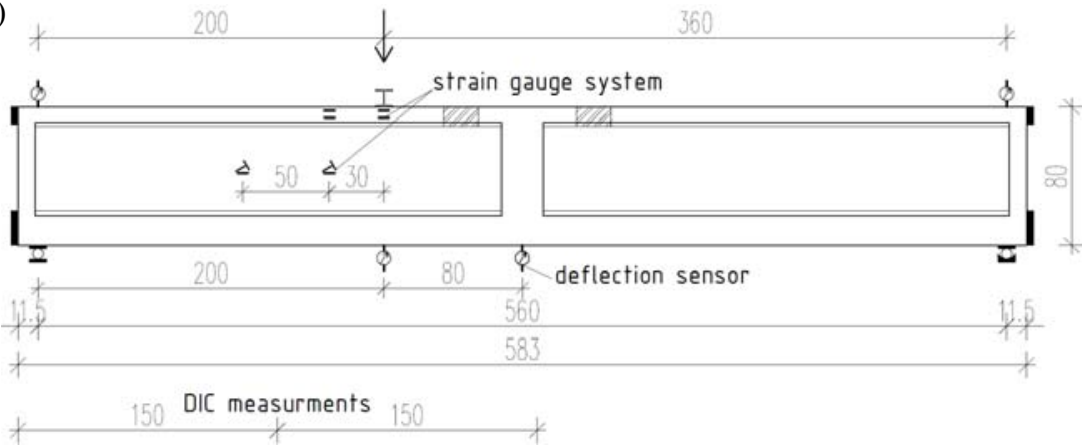

c)

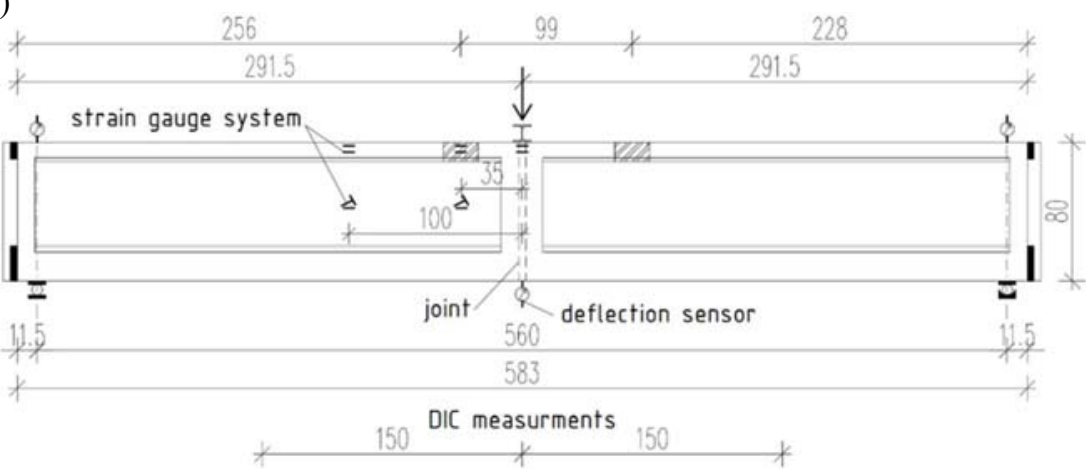

Fig. 4. Experimental setup for a) shear with low shear slenderness KBP-01, b) shear with high shear slenderness KBP-02, c) three-point bending of segmental beam KBP-03.

The KBP-02 element was tested in a static scheme with a shear ratio of about 2.5. According to the predictions, the element showed a beam action characteristic to higher shear slenderness - the failure mode is shown in Fig. 6. The failure due to bending and shear interaction took place at the external load of $\mathrm{P}_{\mathrm{exp}}=886.4 \mathrm{kN}$, i.e. the theoretical transverse force at the support, taking into account the dead weight was $\mathrm{V}_{\exp }=583.6 \mathrm{kN}$. The maximum bending moment in the cross-section of the force application, which caused the concrete to crush in the compressed zone, was $\mathrm{M}_{\exp }=1157.4 \mathrm{kNm}$. The concrete cross-section was separated by two diagonal cracks inclined at an angle of about 30 and $40^{\circ}$. Two bending cracks were also visible - perpendicular on the lower flange and inclined on the web at a slight angle towards the load application point. 


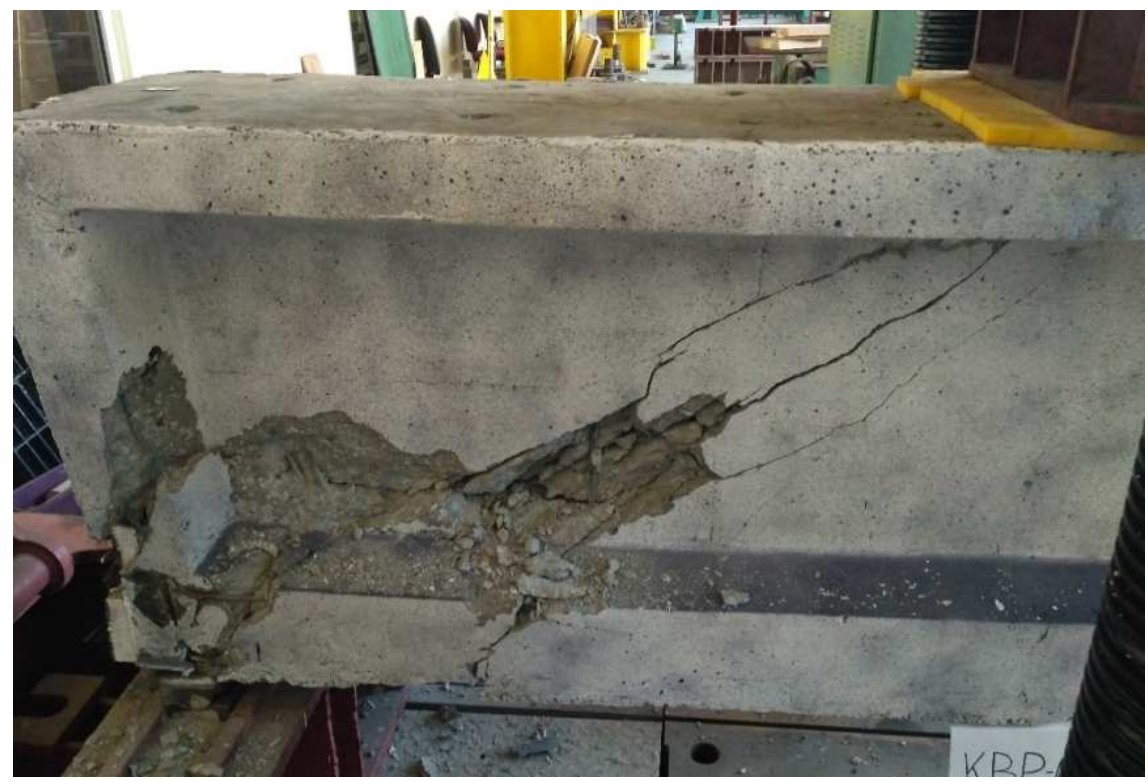

Fig. 5. Failure mode of KBP-01 specimen.

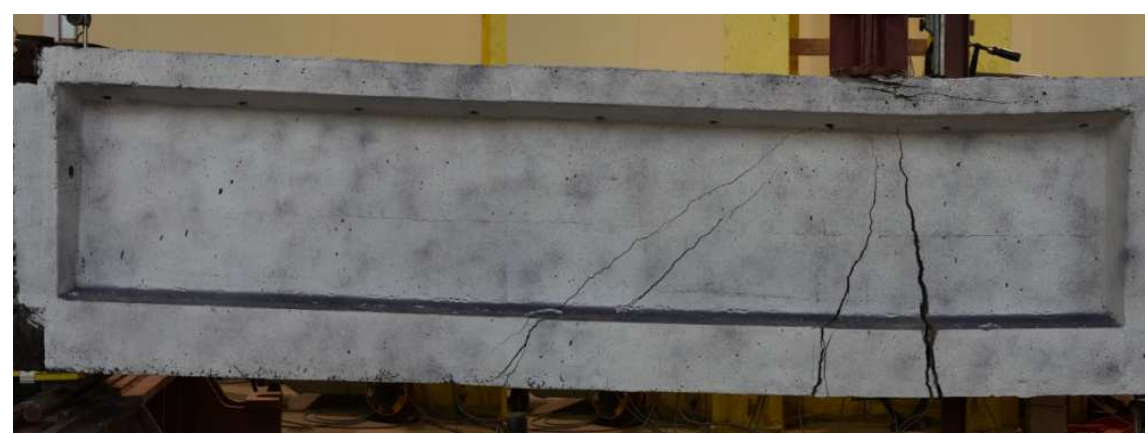

Fig. 6. Failure mode of KBP-02 specimen.

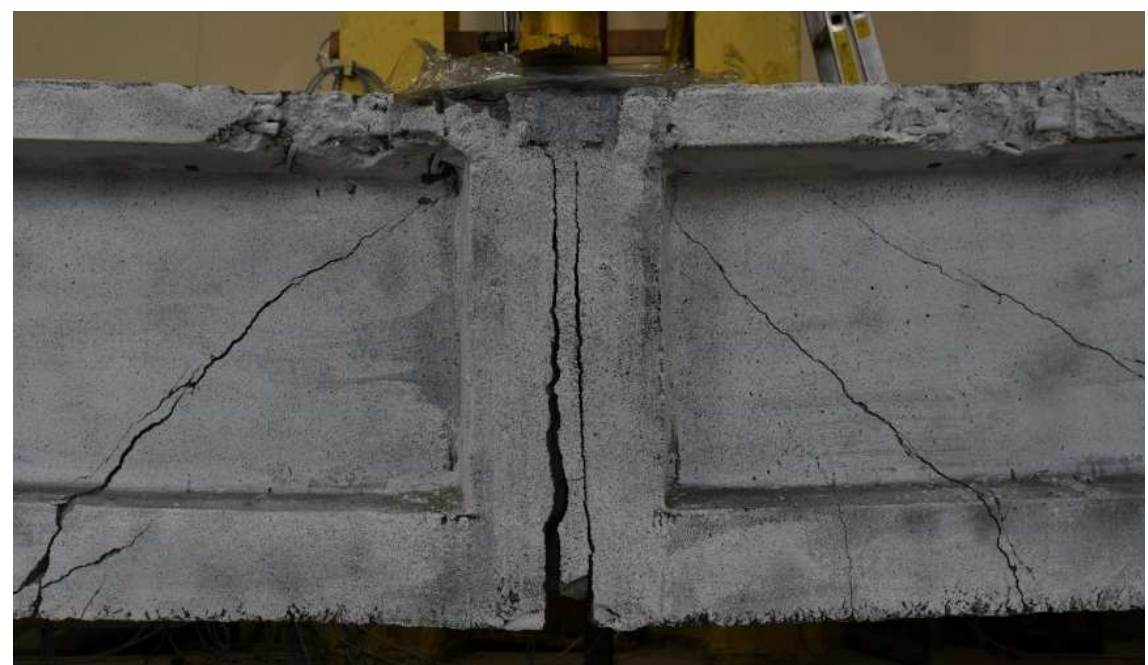

Fig. 7. Failure mode of KBP-03 specimen. 
The test of the KBP-03 element was conducted in a three-point bending scheme with the force applied in the middle of the span, i.e. a static scheme causing the maximum possible bending moment in the beam.

The loading of the KBP-03 element was performed in two stages. In stage I, the beam joint was opened and then the element was unloaded. In stage II, the element was loaded up to the failure. The beam was damaged in the middle of the span with a very large opening of the joint, which resulted in increased elongation of the bottom prestressing cables (Fig. 7). The element failed at the external load of $P_{\exp }=837.7 \mathrm{kN}$, i.e. the failure bending moment, including the dead load, was $\mathrm{M}_{\exp }=1192.1 \mathrm{kNm}$ and the theoretical transverse force at the support at the moment of failure was $\mathrm{V}_{\text {exp }}=432.6 \mathrm{kN}$. The failure of the element was clearly indicated by the opening of the joint and diagonal cracks on both sides. In the final stage of the beam's work, perpendicular cracks connected with diagonal cracks and large deflection increment appeared. The first vertical crack in the joint was observed at the force $\mathrm{P}_{\mathrm{cr}}=286.9$ $\mathrm{kN}$ (cracking moment $\mathrm{M}_{\mathrm{cr}}=421.0 \mathrm{kNm}$ ). The first diagonal crack of the beam was observed with the DIC at the applied force of $454.8 \mathrm{kN}$, thus with the interaction of the vertical force of $241.2 \mathrm{kN}$ and a bending moment of $656.0 \mathrm{kNm}$. The diagonal crack on the strain gauge side of the beam was observed at the force of $498.9 \mathrm{kN}$.

\section{Tests and calculation results}

Table 1 summarizes the calculated shear capacity of the tested elements determined using the models presented in Chapter 3, assuming the mean values of material parameters from the material test results of the beams presented in Table 2 . The prestressing force was estimated on the basis of the initial prestressing force according to the design plans of the elements taking into account the total loss of prestressing force. The angle of inclination of the concrete strut for the shear capacity calculations was assumed as $\theta=40^{\circ}$. Table 1 also takes into account the shear capacity determined from formula (7) even though the minimum transverse reinforcement requirement is not met.

Table 1. Shear capacity of the beam calculated with different models.

\begin{tabular}{|c|c|c|c|c|}
\hline$V_{R d, c}(3)(4)$ & $V_{R d, c}(5)$ & $V_{R d, c}(6)$ & $V_{R d}(7)$ & $V_{R d, \max }(9)$ \\
\hline $106.9 \mathrm{kN}$ & $836.5 \mathrm{kN}$ & $168.0 \mathrm{kN}$ & $261.3 \mathrm{kN}$ & $913.3 \mathrm{kN}$ \\
\hline
\end{tabular}

Table 2. Calculation assumptions.

\begin{tabular}{|c|c|c|c|c|}
\hline$f_{c m}$ & $f_{c t m}$ & $f_{p k}$ & $P_{m t}$ & $\theta$ \\
\hline $56.7 \mathrm{MPa}$ & $4.1 \mathrm{MPa}$ & $1750 \mathrm{MPa}$ & $924 \mathrm{kN}$ & $40^{\circ}$ \\
\hline
\end{tabular}

The results presented in Table 1 show a significant difference in the shear capacities obtained from the individual calculation models. It is worth adding that the capacities calculated with the above-mentioned formulae are almost the same for the RC element (without prestressing effect), whereas after taking into account the prestressing effect the difference is $61.1 \mathrm{kN}$.

The failure mode and the corresponding maximum cross-sectional forces for tests KBP01, KBP-02 and KBP-03 are given in Table 3. Fig. 8 shows the ultimate transverse force of the tested elements related to the shear $a / d$ ratio. 
Table 3. The failure mode and the corresponding maximum cross-sectional forces.

\begin{tabular}{|c|c|c|c|c|}
\hline \multirow{2}{*}{ Beam designation } & \multirow{2}{*}{$\boldsymbol{a} \boldsymbol{d}$} & $\mathbf{M}_{\mathbf{m a x}}$ & $\mathbf{V}_{\max }$ & \multirow{2}{*}{ Failure mode } \\
\cline { 3 - 4 } & & {$[\mathrm{kNm}]$} & {$[\mathrm{kN}]$} & \\
\hline KBP-01 & 1.57 & 1177.1 & 983.9 & Shear - compression \\
\hline KBP-02 & 2.61 & 1157.4 & 583.6 & Bending - shear \\
\hline KBP-03 & 3.66 & 1192.1 & 432.6 & Bending - shear \\
\hline
\end{tabular}

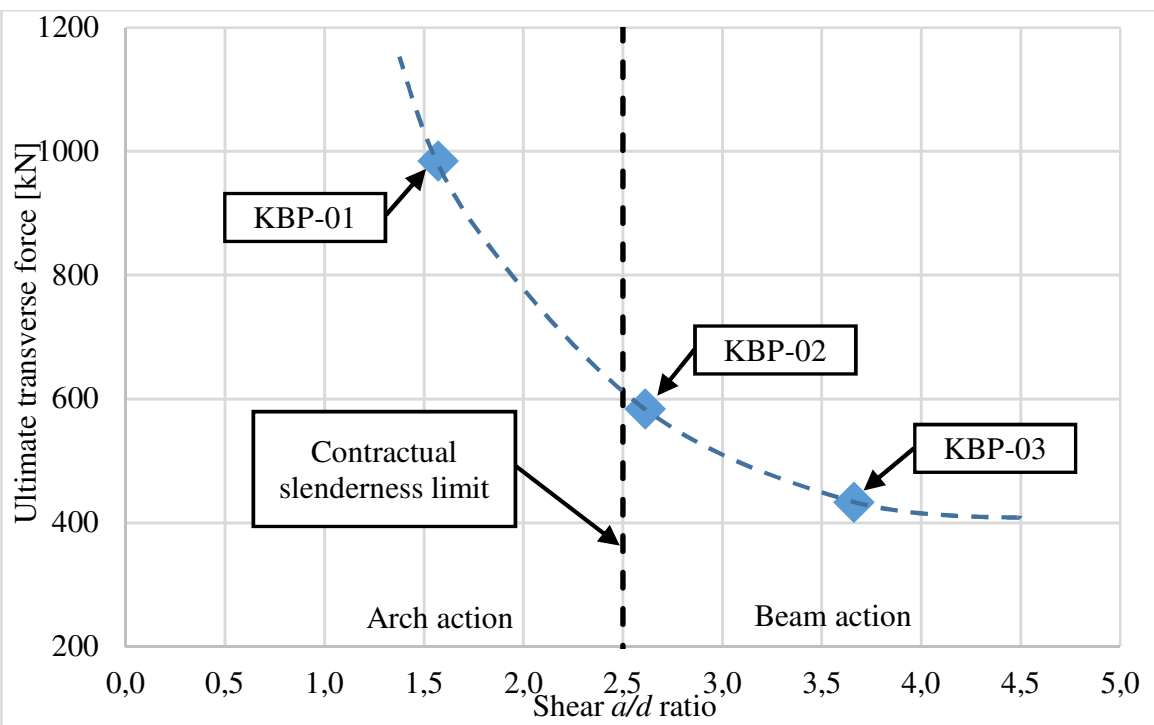

Fig. 8. Ultimate transverse force vs. shear $a / d$ ratio of tested elements.

\section{Conclusions}

The conducted research showed that despite the low shear reinforcement ratio, the elements do not fail in a brittle mode but clearly indicate future destruction by large deflection increments and significant cracking which is an important conclusion for engineering practice.

The tests confirmed that in the case of poorly shear-reinforced prestressed concrete elements, a clear arch action can be distinguished with a low shear span-to-depth ratio, whereas in the case of a higher ratio there is a classical beam action.

The use of the basic calculation models provided in Eurocode 2 and ModelCode 2010 [11], [13] to determine the shear capacity may lead to serious differences with the actual load capacity of existing members. The experimental shear capacities of KBP-02, KBP-03 elements are significantly higher than the one calculated by means of basic standard models. The best convergence was achieved using the model given in Model Code 2010, which takes into account the interaction of concrete and stirrup in the total design shear resistance. In the case of the KBP-01 element, the shear capacity was exhausted with the crushing of the compressed concrete strut. Assuming the observed slope of the strut, its calculated capacity is equal to $913.3 \mathrm{kN}$ and it is slightly lower than the value obtained in the test. This can be explained by the reduction of $b_{w}$ value due to the cable ducts (specified in the standards) while in fact, a good filling of the duct with cement slurry reduces the negative influence of the ducts and thus increases cross-sectional capacity. 


\section{References}

1. W. Derkowski, R. Walczak, Proceedings of the fib Symposium 2019, 1507-1514 (2019).

2. T. Godycki-Ćwirko, Ścinanie w żelbecie (Arkady, Warszawa 1968).

3. G.N.J. Kani, J. ACI 63, 6 675-692 (1966).

4. I.A. Bukhari, S. Ahmad, Arab. J. Sci. Eng. 33, 2B 321-335 (2008).

5. A.H. Shuaib, D.M. Lue, ACI Stru. J. 84, 4 330-341 (1987).

6. T. Zsutty, ACI J. 65, 11 943-951 (1968).

7. M. Słowik, Nośność na ścinanie zginanych elementów żelbetowych bez zbrojenia poprzecznego (Politechnika Lubelska, Lublin 2016).

8. J. Walraven, J. str. Div. 107, ST11, 2245-2270 (1981).

9. K. Kobayashi Proceedings of the Tenth Word Conference on Earthquake Engineering, 3101-3108 (1992).

10. A. Hillerborg, M. Modeer, P.E. Petersson, Cem. Conc. Res. 6 773-782 (1976).

11. EN 1992-1-1:2004, CEN (2004).

12. Z. Zieliński Inż. Bud. 2, 14 (1961).

13. J. Walraven et al., fib Model Code 2010 (2012).

14. M.F. Ruiz, A. Muttoni, ACI Str. J. 105, 3, 308-317 (2008).

15. P. Huber, T. Huber, J. Kollegger, fib Workshop in Zurich, 33-49 (2016). 